\title{
Mini Review \\ Translational Science: how experimental research has contributed to the understanding of spontaneous Physical Activity and Energy Homeostasis
}

\author{
Izabelle D Benfato \\ Thaís L Moretto \\ Marcela Barthichoto \\ Francine $\mathrm{P}$ de Carvalho \\ Camila A M de Oliveira \\ Universidade Federal de São Paulo, Santos, SP, Brasil
}

\begin{abstract}
Spontaneous physical activity (SPA) consists of all daily living activities other than volitional exercise (e.g. sports and fitness-related activities). SPA is an important component of energy expenditure and may protect from overweight and obesity. Little is known about the biological regulation of SPA, but animal research has contributed significantly to expand our knowledge in this field. Studies in rodents have shown that SPA is influenced by nutrients and volitional exercise. High-fat diet seems to decrease SPA, which contributes to weigh gain. Volitional exercise may also reduce SPA, helping to explain the commonly reported low efficiency of exercise to cause weight loss, and highlighting the need to find a volume/intensity of exercise to maximize total daily energy expenditure. Animal studies have also allowed for the identification of some brain areas and chemical mediators involved in SPA regulation. These discoveries could enable the development of new therapeutics aiming to enhance SPA.
\end{abstract}

Keywords: energy balance, free-living activity, volitional exercise, sedentary behavior.

\section{Introduction}

Lack of physical activity contributes to the disruption of energy homeostasis, favoring a positive energy balance. Chronically, the result is overweight and obesity ${ }^{1}$. Thus, in the current scenario of obesity epidemic, it is not surprising the alarming numbers regarding inactivity. In 2012, worldwide, $31.1 \%$ of adults were considered physically inactive, with proportions ranging from $17.0 \%$ in south East Asia to about $43 \%$ in the Americas and the eastern Mediterranean ${ }^{2}$.

This panorama can be explained by the increase in time spent in sedentary behaviors (activities with very low energy expenditure, such as TV viewing, computer and game-console use in the sitting position, workplace sitting, and time spent in automobiles) at workplace, at leisure, at home and transport, over decades $^{3}$. An assessment from the National Health and Nutrition Examination Survey in the United States 2003-2004 revealed that many adults spend $70 \%$ or more of their waking hours sitting, 30\% in light activities and little or no time in exercise ${ }^{4}$.

Sitting time is positively associated with increased risk for cardiovascular disease and all-cause mortality. Notably, even for those meeting the public-health guidelines on physical activity, sitting for prolonged periods is associated with adverse outcomes ${ }^{5,6}$. Thus, it is clear the health benefits one can obtain by reducing the time spent on sedentary behavior, even if performing moderate to vigorous physical activities. This highlights the importance of low-intensity physical activity, whose contribution to either health or to total daily energy expenditure is usually neglected ${ }^{5}$.

Whereas it is estimated that physical inactivity is responsible for $6 \%$ of cases of coronary artery disease, $7 \%$ of cases of type 2 diabetes mellitus and $10 \%$ of breast and colon cancers ${ }^{7}$, strong evidence indicates that reducing physical inactivity by $10 \%$ to $25 \%$ could avoid 533,000 to 3 million deaths per year, respectively ${ }^{7}$. Besides, high levels of physical activity are associated with a gradual increase in life expectancy ${ }^{8}$.

Environmental (e.g. drive-through, city architecture) and socioeconomic (e.g. violence, lack of opportunity for leisure) factors are some of the elements known to affect physical activity negatively ${ }^{9}$. The biological aspects, however, remain poorly understood. In this review we discuss the contributions of animal studies to the understanding of the biological determinants of spontaneous physical activity, which encompasses all forms of activities other than volitional exercise (e.g. sports and fitnessrelated activities), and its impact on energy homeostasis.

\section{Components of Energy Homeostasis}

To be in a neutral energy balance, or to achieve energy homeostasis, energy intake and expenditure must be also in balance ${ }^{10}$. As shown in Figure 1, in humans and rodents energy expenditure includes basal metabolic rate (BMR), the thermic effect of food (TEF), and activity thermogenesis (AT) ${ }^{11}$. BMR is the 
energy expended when an individual is laying down at rest in the postabsorptive state, and corresponds to about $60 \%$ to $70 \%$ of total daily energy expenditure, or TDEE ${ }^{12}$. BMR can be affected by either resistance or endurance training. As non-fat mass is a major factor in determining basal metabolic rate ${ }^{13}$, the increase in muscle mass as a result of resistance training can consequently increase BMR. With respect to endurance exercise, it has been shown to increase the production of the thermogenic myokine irisin, which drives the browning of white fat ${ }^{14}$. The energy spent for digestion, absorption and processing of food, or TEF, varies between $5 \%$ and $15 \%$ of TDEE. Finally, activity thermogenesis is the energy used for spontaneous muscle contractions, body movements (physical activity), and is the component of energy expenditure which varies the most $\mathrm{t}^{12}$. Thermoregulation is not depicted in Figure 1, as people wear appropriate clothes and so the energy expended to maintain body temperature is neglected. Rodents, however, are maintained in animal facilities at temperatures below their thermoneutral zone $\left(21^{\circ} \mathrm{C}\right)$, implicating a substantial cost of thermoregulation ${ }^{10}$.

Physical activity can be subdivided into volitional exercise (VE) and spontaneous physical activity (SPA). Whereas volitional exercise is all kind of exercise done in a systematic way (e.g. sports and fitness-related activity), SPA refers to activities other than VE, such as daily living activities, yard work, fidgeting, posture maintenance, and non-specific ambulatory behavior ${ }^{15}$. The energy spent only in SPA is called non-exercise activity thermogenesis (NEAT), and for those individuals not engaged in any form of volitional exercise, NEAT is the sole responsible for AT. NEAT can vary from $100 \mathrm{kcal}$ to $800 \mathrm{kcal} /$ day in very active individuals ${ }^{15,16}$, and the importance of NEAT for energy homeostasis has been demonstrated in studies with humans ${ }^{17}$ and rodents ${ }^{18,19}$.

For rodents, SPA refers to all form of activities including ambulatory and non-ambulatory behavior ${ }^{10}$. Caution is needed regarding wheel running, which is commonly used as a model of volitional exercise and is not equivalent to SPA, as it engages different neural and physiological mechanisms ${ }^{15,20}$. Swimming ${ }^{21,22}$ and treadmill running ${ }^{23}$ are also commonly used as an equivalent form of volitional exercise in rodents.
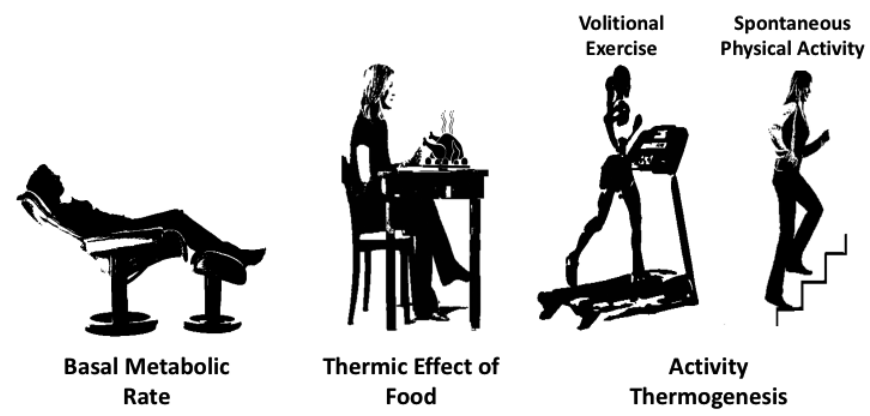

Figure 1. Main components of energy expenditure in humans: basal metabolic rate, thermic effect of food, and activity thermogenesis. Activity thermogenesis is subdivided into volitional exercise and spontaneous physical activity. For those individuals not engaged in any form of volitional exercise, SPA is the sole responsible for activity thermogenesis.

\section{Nutrients, Energy Intake, and Spontaneous Physical Activity}

Feeding influences energy homeostasis primarily due to its effect on energy intake. However, nutrients and the caloric content of the diet can also affect SPA and, consequently, energy expenditure ${ }^{24,25}$. As diet modification, both in terms of calorie density and also macronutrients, is a common tool to promote body weight loss, a more comprehensive view of how dietchanging can affect total daily energy expenditure is of great importance. The contributions from animal studies to this field are discussed below.

\section{High-fat diet}

The deleterious peripheral and central effects of high-fat diet are well established ${ }^{26,27}$. Interestingly, high-fat diet has also been shown to decrease spontaneous physical activity in rodents ${ }^{18,24}$. This effect could be seen as early as after a few hours on the diet, and it remained throughout the 21 days in which mice received the diet rich in fat ${ }^{18}$. According to the authors, the reduction of locomotor activity had an essential role in weight gain and obesity. They found that the energy intake and the energy absorbed were higher in high-fat than in standard-diet fed mice only in the first 24 hours, whereas body weight and fat gain increased all over ${ }^{18}$.

\section{Low-protein diet}

Perhaps for methodological issues ${ }^{15,20}$, studies associating low-protein diet and locomotor activity are still scarce and controversial. Rats suckling in large litters and therefore with limited access to food seem to have higher levels of physical activity, even when they have free access to food after weaning. Similarly, rats whose mothers were fed a low-protein diet during pregnancy and lactation (5\% protein) were also more active ${ }^{28}$. However, Dúran et al. ${ }^{29}$ found no alterations in overall activity level (measured by radiotelemetry) in rats with a history of protein malnutrition. They observed, instead, alterations in the pattern of locomotor activity ${ }^{29}$.

\section{High-protein diet}

Yamaoka et al. ${ }^{30}$ found that male Sprague-Dawley rats fed a highprotein, carbohydrate-free diet decreased locomotor activity but had increased body temperature and reduced body weight when compared to male rats fed with a normal-protein diet. Differently, Oishi et al. ${ }^{31}$ found no differences on locomotor activity and body temperature in mice receiving a low-carbohydrate high-protein diet. Thus, whether the protein content of the diet modulates spontaneous physical activity remains to be determined. 


\section{Calorie restriction}

Calorie restriction affects SPA differently depending on factors such as severity, duration of food deprivation, and species. In Wistar rats, whereas moderate $(30 \%)$ feed restriction did not change SPA, severe (approximately 80\%) restriction reduced spontaneous activity, resulting in energetic economy ${ }^{32}$. In another study, chronic caloric restriction (CR) increased SPA during the time interval preceding anticipation of food in obesity-prone and Sprague-Dawley rats, but not in obesity-resistant rats, which already have elevated basal SPA ${ }^{33}$. Brzek et al. ${ }^{25}$ investigated the effect of a moderate CR on SPA in mice divergently selected for high or low basal metabolic rate. CR increased total SPA and SPA intensity in both lines, but the latter increased more in the group selected for low basal metabolic rate. Mice selected for high basal metabolic rate have increased basal SPA, and maintained their genetically determined high SPA even under $\mathrm{CR}^{25}$. In general, $\mathrm{CR}$ results in an acute increase in activity, whereas severe restriction decreases SPA, which then conserves energy. However, there is considerable influence of the genetic background.

\section{Volitional Exercise and Spontaneous Physical Activity}

Volitional exercise is one of the most used tools to induce negative energy balance and weight loss. However, not rarely, the results are disappointing and the observed body weight reduction is less than predicted ${ }^{34}$. Besides the well-known increase in energy intake, volitional exercise can interfere negatively with $\mathrm{SPA}^{35,36}$, and these compensatory behaviors may minimize the exercise efficiency to reduce body weight.

Copes et al. ${ }^{36}$ found that daily free access to a running wheel, a form of volitional exercise in rodents, decreased SPA. In the same line we found that both lean and diet-induced obese mice, which had free access to running wheels 5 days per week, had reduced SPA in the resting days ${ }^{35}$. As wheel running does not allow for the control of volume and intensity, the exercise load might have been inappropriate, triggering a compensatory decrease in SPA. Interestingly, when aerobic swimming exercise at individualized intensity was used, it avoided the decline in SPA observed in non-trained rats after 12 weeks ${ }^{22}$.

Thus, an adequate amount/intensity of volitional exercise should be established so that SPA could either be kept at a constant level or even increased. As every body movement has its associated energy cost, increasing volitional exercise but reducing SPA could result in no change in total daily energy expenditure (Fig. 2). In our study, as a result of both increased caloric intake and decreased SPA, wheel running failed to decrease body weight in lean and obese mice ${ }^{35}$. Accordingly, Morio et $a l .{ }^{37}$ found that a progressive endurance training in elderly individuals did not change their total daily energy expenditure due to a compensatory decrease in free-living activities. On the other hand, Rosenkilde et al..$^{38}$ showed that moderate exercise accumulated a negative balance $80 \%$ greater than expected, without increasing energy intake. They speculate this greaterthan-expected energy expenditure could have been caused by an increase in SPA. In sharp contrast, the group performing the higher-dose exercise accumulated a negative balance $20 \%$ less effective than expected ${ }^{38}$.

Thus, it is clear that when exercise is used as a tool to promote negative energy balance, the compensatory behavior it triggers must be taken into account. Besides the increase in energy intake, a decrease in SPA might compromise the successful use of exercise as a mean to induce body weight loss. In this context, animal studies provide a unique opportunity to investigate how SPA is regulated, what are the mechanisms involved in compensation, and how to avoid SPA decline. We believe a better understanding of SPA can impact directly exercise programs aiming for weight loss, contributing to the fight against obesity.
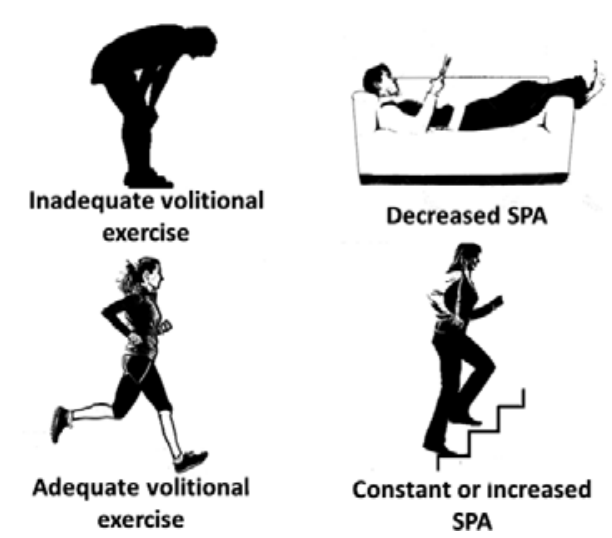

Below-than-expected negative balance or unchanged TDEE

Expected or abovethan-expected negative balance

Figure 2. Possible interactions between volitional exercise, spontaneous physical activity (SPA), and the consequences for energy balance. This figure is an oversimplification of the compensatory events triggered by exercise, and only changes in SPA are showed. TDEE: total daily energy expenditure.

\section{Aging and Spontaneous Physical Activity}

Aging is a process marked by several metabolic and physical changes ${ }^{39}$. These changes, associated with the sedentary behavior characteristic of the aging process, make older people more susceptible to chronic diseases ${ }^{40,41}$.

There is a clear age-related decrease in SPA ${ }^{42}$ and energy expenditure ${ }^{39}$. Additionally, elderly people seem to be especially susceptible to compensation in SPA caused by volitional exercise. Poehlman ${ }^{43}$ observed a $62 \%$ reduction in NEAT after voluntary exercise in older people. As a consequence, total daily energy expenditure did not change despite volitional exercise. Similar results were found by Morio et al..$^{37}$.

The understanding of the mechanisms involved in the reduction of SPA during aging, including the apparently higher susceptibility to volitional exercise-induced decrease in SPA, could enable the adoption of strategies at critical periods of life to combat sedentary lifestyle and the associated comorbidities. In this scenario, rodent models are sorely needed due to their relatively short lifespan. As an example, mice are considered middle-aged when 40 weeks old and senescent when 72 weeks old $^{44,45}$, making studies on aging much more viable in rodents than in humans. Some advances have already been achieved, such as the role of hypothalamic neuropeptides on the decrease of $\mathrm{SPA}^{42}$, as discussed in the next session. 


\section{Central Regulation of Spontaneous Physical Activity}

Although it is not clear how SPA is regulated, due to animal studies some areas within the central nervous system (CNS), as well as some neuropeptides and hormones, are emerging as candidates. One of the CNS regions is the hypothalamus, more specifically the arcuate nucleus (ARC). ARC is known to play an essential role in energy balance, connecting afferent signals with central circuits, and transmitting efferent commands to control food intake, locomotor activity, and peripheral cell metabolism ${ }^{15,46}$. In addition to hypothalamus, there are other regions in the CNS which seem to regulate SPA and NEAT, which include: the mesencephalic locomotor region, locus coeruleus (LC), ventral tegmental area (VTA), substantia nigra (SN), tuberomammillary nuclei (TMN), pedunculopontine and laterodorsal tegmental nuclei, nucleus accumbens (NAcc), and striatum ${ }^{47}$.

NPY, a neuropeptide expressed mainly in a subtype of neurons in ARC, was recently shown to increase SPA. Intracerebroventricular (i.c.v.) administration of NPY resulted in a shift of metabolism towards lipid storage and an increased use of carbohydrates, while at the same time increasing locomotor activity, energy expenditure, and body temperature ${ }^{48}$. Pfluger et al.$^{49}$ observed the same increase of SPA following NPY i.c.v. administration. On the other hand, AgRP i.c.v. administration resulted in a significant decrease of SPA and increased food intake ${ }^{49}$.

Orexin A (hypocretin), another neuropeptide, has also been shown to be involved in the central regulation of $\mathrm{SPA}^{42}$. Orexin neurons are concentrated in the lateral hypothalamus ( $\mathrm{LH})$, perifornical area, and dorsomedial hypothalamus ${ }^{42,50}$. Some studies in rodents suggest the effect of orexin A on SPA is more relevant to energy balance than its role on the control of food intake ${ }^{51}$. Orexin A infusion in LC promotes SPA but not food intake, suggesting its signaling in LC promotes negative energy balance and reduction of adiposity ${ }^{51}$. In another study by Teske et $\mathrm{al}^{52}$, it was shown that orexin projections from the LH stimulates orexin and dopamine signaling in the SN and promotes SPA. Importantly, a reduced activity of hypothalamic orexin signaling seems to be related to the decrease in spontaneous physical activity during aging ${ }^{42}$.

In relation to hormones, insulin and leptin emerge as potential modulators of SPA. Hennige et al.$^{53}$ showed that insulin i.c.v. injection promotes SPA in lean but not in diet-induced obese mice, which develop hypothalamic resistance to insulin ${ }^{53}$. In addition, the pharmacological inhibition of insulin signaling in hypothalamus also decreased the locomotor activity in mice ${ }^{54}$. With respect to leptin, the positive association between this hormone and physical activity in rodents was first shown by Pelleymounter et $a l .55$. Over the years, other studies have demonstrated the effect of leptin in increasing locomotor activity ${ }^{56,57}$. In humans, however, the results are contradictory. Belcher et $a l .{ }^{58}$ observed that high levels of leptin preceded a fall in the levels of physical activity in female children with obesity risk. A negative correlation between leptin levels and physical activity in healthy girls, independent of puberty stage and adiposity, has also been observed. However, the same correlation was not observed in healthy boys ${ }^{59}$.
Besides the hormones and neuropeptides mentioned, there are other molecules which may be involved in the regulation of SPA, including cholecystokinin (CCK), corticotropin-releasing hormone (CRH), neuromedin U (NMU), and ghrelin ${ }^{47}$. The role of brain-derived neurotrophic factor (BDNF) in stimulating locomotor activity has also been demonstrated ${ }^{60}$.

\section{Conclusion}

The worryingly high number of inactive individuals together with data showing that physical inactivity is more fatal than obesity per se $e^{61}$ make evident the urge of approaches to stimulate SPA. Animal studies have allowed some important advances in our understanding of the neuroendocrine mechanisms modulating SPA and how SPA can be affected by factors such as nutrients, volitional exercise, and aging. This knowledge can have implications for the development of new pharmacological and non-pharmacological strategies (diet and volitional exercise) to combat sedentary behavior, obesity, and the associated comorbidities. Additional studies are needed to further elucidate the biological regulation of SPA.

\section{References}

1. Donahoo WT, Levine JA, Melanson EL. Variability in energy expenditure and its components. Curr Opin Clin Nutr Metab Care. 2004;7(6):599-605.

2. Hallal PC, Andersen LB, Bull FC, Guthold R, Haskell W, Ekelund $\mathrm{U}$, et al. Global physical activity levels: surveillance progress, pitfalls, and prospects. Lancet. 2012;380(9838):247-57.

3. Sedentary Behaviour Research Network. Letter to the editor: standardized use of the terms "sedentary" and "sedentary behaviours". Appl Physiol Nutr Metab. 2012;37(3):540-2.

4. Matthews CE, Chen KY, Freedson PS, Buchowski MS, Beech BM, Pate RR, et al. Amount of time spent in sedentary behaviors in the United States, 2003-2004. Am J Epidemiol. 2008;167(7):875-81.

5. Owen N, Healy GN, Matthews CE, Dunstan DW. Too much sitting: the population health science of sedentary behavior. Exerc Sport Sci Rev. 2010;38(3):105-13.

6. Meneguci J, Santos DAT, Silva RB, Santos RG, Sasaki JE, Tribess $\mathrm{S}$, et al. Comportamento sedentário: conceito, implicações fisiológicas e os procedimentos de avaliação/Sedentary behavior: concept, physiological implications and the assessment procedures. Motricidade. 2015;11(1):160.

7. Lee IM, Shiroma EJ, Lobelo F, Puska P, Blair SN, Katzmarzyk PT, et al. Effect of physical inactivity on major non-communicable diseases worldwide: an analysis of burden of disease and life expectancy. Lancet. 2012;380(9838):219-29.

8. Moore SC, Patel AV, Matthews CE, Berrington de Gonzalez A, Park Y, Katki HA, et al. Leisure time physical activity of moderate to vigorous intensity and mortality: a large pooled cohort analysis. PLoS Med. 2012;9(11):e1001335.

9. Levine JA. Sick of sitting. Diabetologia. 2015;58(8):1751-8.

10. Garland T, Schutz H, Chappell MA, Keeney BK, Meek TH, Copes LE, et al. The biological control of voluntary exercise, 
spontaneous physical activity and daily energy expenditure in relation to obesity: human and rodent perspectives. J Exp Biol. 2011;214(Pt 2):206-29.

11. Even PC, Nadkarni NA. Indirect calorimetry in laboratory mice and rats: principles, practical considerations, interpretation and perspectives. Am J Physiol Regul Integr Comp Physiol. 2012;303(5):R459-76.

12. Hill JO. Understanding and addressing the epidemic of obesity: an energy balance perspective. Endocr Rev. 2006;27(7):750-61.

13. Johnstone AM, Murison SD, Duncan JS, Rance KA, Speakman JR. Factors influencing variation in basal metabolic rate include fat-free mass, fat mass, age, and circulating thyroxine but not sex, circulating leptin, or triiodothyronine. Am J Clin Nutr. 2005;82(5):941-8.

14. Boström P, Wu J, Jedrychowski MP, Korde A, Ye L, Lo JC, et al. A PGC1- $\alpha$-dependent myokine that drives brown-fatlike development of white fat and thermogenesis. Nature. 2012;481(7382):463-8.

15. Novak CM, Levine JA. Central neural and endocrine mechanisms of non-exercise activity thermogenesis and their potential impact on obesity. J Neuroendocrinol. 2007;19(12):923-40.

16. Levine JA. Nonexercise activity thermogenesis (NEAT): environment and biology. Am J Physiol Endocrinol Metab. 2004;286(5):E675-85.

17. Levine JA, Eberhardt NL, Jensen MD. Role of nonexercise activity thermogenesis in resistance to fat gain in humans. Science. 1999;283(5399):212-4.

18. Bjursell M, Gerdin AK, Lelliott CJ, Egecioglu E, Elmgren A, Törnell $\mathrm{J}$, et al. Acutely reduced locomotor activity is a major contributor to Western diet-induced obesity in mice. Am J Physiol Endocrinol Metab. 2008;294(2):E251-60.

19. Teske JA, Billington CJ, Kuskowski MA, Kotz CM. Spontaneous physical activity protects against fat mass gain. Int J Obes (Lond). 2012;36(4):603-13.

20. Sherwin CM. Voluntary wheel running: a review and novel interpretation. Anim Behav. 1998;56(1):11-27.

21. Costa Júnior JM, Rosa MR, Protzek AO, de Paula FM, Ferreira SM, Rezende LF, et al. Leucine supplementation does not affect protein turnover and impairs the beneficial effects of endurance training on glucose homeostasis in healthy mice. Amino Acids. 2015;47(4):745-55.

22. Scariot PP, Manchado-Gobatto FeB, Torsoni AS, Dos Reis IG, Beck WR, Gobatto CA. Continuous Aerobic Training in Individualized Intensity Avoids Spontaneous Physical Activity Decline and Improves MCT1 Expression in Oxidative Muscle of Swimming Rats. Front Physiol. 2016;7:132.

23. Costa-Júnior JM, Ferreira SM, Protzek AO, Santos GJ, Cappelli AP, Silveira LR, et al. Endurance training inhibits insulin clearance and IDE expression in Swiss mice. PLoS One. 2015;10(3):e0118809.

24. Wong CK, Botta A, Pither J, Dai C, Gibson WT, Ghosh S. A high-fat diet rich in corn oil reduces spontaneous locomotor activity and induces insulin resistance in mice. J Nutr Biochem. 2015;26(4):319-26.

25. Brzęk P, Gębczyński AK, Książek A, Konarzewski M. Effect of calorie restriction on spontaneous physical activity and body mass in mice divergently selected for basal metabolic rate (BMR). Physiol Behav. 2016;161:116-22.

26. Winzell MS, Ahrén B. The high-fat diet-fed mouse: a model for studying mechanisms and treatment of impaired glucose tolerance and type 2 diabetes. Diabetes. 2004;53 Suppl 3:S215-9.

27. Thaler JP, Yi CX, Schur EA, Guyenet SJ, Hwang BH, Dietrich $\mathrm{MO}$, et al. Obesity is associated with hypothalamic injury in rodents and humans. J Clin Invest. 2012;122(1):153-62.

28. Parízková J. Interaction between physical activity and nutrition early in life and their impact on later development. Nutr Res Rev. 1998;11(1):71-90.

29. Durán P, Cintra L, Galler JR, Tonkiss J. Prenatal protein malnutrition induces a phase shift advance of the spontaneous locomotor rhythm and alters the rest/activity ratio in adult rats. Nutr Neurosci. 2005;8(3):167-72.

30. Yamaoka I, Hagi M, Doi M. Circadian changes in core body temperature, metabolic rate and locomotor activity in rats on a high-protein, carbohydrate-free diet. J Nutr Sci Vitaminol (Tokyo). 2009;55(6):511-7.

31. Oishi K, Uchida D, Itoh N. Low-carbohydrate, high-protein diet affects rhythmic expression of gluconeogenic regulatory and circadian clock genes in mouse peripheral tissues. Chronobiol Int. 2012;29(7):799-809.

32. Even PC, Nicolaïdis S. Adaptive changes in energy expenditure during mild and severe feed restriction in the rat. Br J Nutr. 1993;70(2):421-31.

33. Teske JA, Kotz CM. Effect of acute and chronic caloric restriction and metabolic glucoprivation on spontaneous physical activity in obesity-prone and obesity-resistant rats. Am J Physiol Regul Integr Comp Physiol. 2009;297(1):R176-84.

34. King NA, Caudwell P, Hopkins M, Byrne NM, Colley R, Hills AP, et al. Metabolic and behavioral compensatory responses to exercise interventions: barriers to weight loss. Obesity (Silver Spring). 2007;15(6):1373-83.

35. de Carvalho FP, Benfato ID, Moretto TL, Barthichoto M, de Oliveira CA. Voluntary running decreases nonexercise activity in lean and diet-induced obese mice. Physiol Behav. 2016;165:249-56.

36. Copes LE, Schutz H, Dlugosz EM, Acosta W, Chappell MA, Garland T. Effects of voluntary exercise on spontaneous physical activity and food consumption in mice: Results from an artificial selection experiment. Physiol Behav. 2015;149:86-94.

37. Morio B, Montaurier C, Pickering G, Ritz P, Fellmann N, Coudert $\mathrm{J}$, et al. Effects of 14 weeks of progressive endurance training on energy expenditure in elderly people. Br J Nutr. 1998;80(6):511-9.

38. Rosenkilde M, Auerbach P, Reichkendler MH, Ploug T, Stallknecht BM, Sjödin A. Body fat loss and compensatory mechanisms in response to different doses of aerobic exercise--a randomized controlled trial in overweight sedentary males. Am J Physiol Regul Integr Comp Physiol. 2012;303(6):R571-9.

39. Michalakis K, Goulis DG, Vazaiou A, Mintziori G, Polymeris A, Abrahamian-Michalakis A. Obesity in the ageing man. Metabolism. 2013;62(10):1341-9.

40. Ramalho JR, Mambrini JV, César CC, de Oliveira CM, Firmo JO, Lima-Costa MF, et al. Physical activity and all-cause mortality among older Brazilian adults: 11-year follow-up of the Bambuí Health and Aging Study. Clin Interv Aging. 2015;10:751-8. 
41. Sprod J, Ferrar K, Olds T, Maher C. Changes in sedentary behaviours across the retirement transition: a systematic review. Age Ageing. 2015;44(6):918-25.

42. 42. Zink AN, Perez-Leighton CE, Kotz CM. The orexin neuropeptide system: physical activity and hypothalamic function throughout the aging process. Front Syst Neurosci. 2014;8:211.

43. Poehlman ET, Gardner AW, Goran MI. Influence of endurance training on energy intake, norepinephrine kinetics, and metabolic rate in older individuals. Metabolism. 1992;41(9):941-8.

44. Stowie AC, Glass JD. Longitudinal Study of Changes in Daily Activity Rhythms over the Lifespan in Individual Male and Female C57BL/6J Mice. J Biol Rhythms. 2015;30(6):563-8.

45. Kevin Flurkey JMC, D.E. Harrison. The Mouse in Biomedical Research (Second Edition). Chapter 20 - Mouse Models in Aging Research 2007.

46. Wynne K, Stanley S, McGowan B, Bloom S. Appetite control. J Endocrinol. 2005;184(2):291-318.

47. Teske JA, Billington CJ, Kotz CM. Neuropeptidergic mediators of spontaneous physical activity and non-exercise activity thermogenesis. Neuroendocrinology. 2008;87(2):71-90.

48. Su Y, Foppen E, Fliers E, Kalsbeek A. Effects of intracerebroventricular administration of neuropeptide $\mathrm{Y}$ on metabolic gene expression and energy metabolism in male rats. Endocrinology. 2016:en20161083.

49. Pfluger PT, Castañeda TR, Heppner KM, Strassburg S, Kruthaupt T, Chaudhary N, et al. Ghrelin, peptide YY and their hypothalamic targets differentially regulate spontaneous physical activity. Physiol Behav. 2011;105(1):52-61.

50. Peyron C, Tighe DK, van den Pol AN, de Lecea L, Heller HC, Sutcliffe JG, et al. Neurons containing hypocretin (orexin) project to multiple neuronal systems. J Neurosci. 1998;18(23):9996-10015.

51. Teske JA, Perez-Leighton CE, Billington CJ, Kotz CM. Role of the locus coeruleus in enhanced orexin A-induced spontaneous physical activity in obesity-resistant rats. Am J Physiol Regul Integr Comp Physiol. 2013;305(11):R1337-45.

52. Teske JA, Billington CJ, Kotz CM. Mechanisms underlying obesity resistance associated with high spontaneous physical activity. Neuroscience. 2014;256:91-100.

53. Hennige AM, Sartorius T, Lutz SZ, Tschritter O, Preissl H, Hopp $\mathrm{S}$, et al. Insulin-mediated cortical activity in the slow frequency range is diminished in obese mice and promotes physical inactivity. Diabetologia. 2009;52(11):2416-24.

54. Bandaru SS, Lin K, Roming SL, Vellipuram R, Harney JP. Effects of PI3K inhibition and low docosahexaenoic acid on cognition and behavior. Physiol Behav. 2010;100(3):239-44.

55. Pelleymounter MA, Cullen MJ, Baker MB, Hecht R, Winters D, Boone T, et al. Effects of the obese gene product on body weight regulation in ob/ob mice. Science. 1995;269(5223):540-3.
56. Morton GJ, Kaiyala KJ, Fisher JD, Ogimoto K, Schwartz MW, Wisse BE. Identification of a physiological role for leptin in the regulation of ambulatory activity and wheel running in mice. Am J Physiol Endocrinol Metab. 2011;300(2):E392-401.

57. Ribeiro AC, Ceccarini G, Dupré C, Friedman JM, Pfaff DW, Mark AL. Contrasting effects of leptin on food anticipatory and total locomotor activity. PLoS One. 2011;6(8):e23364.

58. Belcher BR, Chou CP, Nguyen-Rodriguez ST, Hsu YW, ByrdWilliams CE, McClain AD, et al. Leptin predicts a decline in moderate to vigorous physical activity in minority female children at risk for obesity. Pediatr Obes. 2013;8(1):70-7.

59. Romon M, Lafay L, Bresson JL, Oppert JM, Borys JM, Kettaneh A, et al. Relationships between physical activity and plasma leptin levels in healthy children: the Fleurbaix-Laventie Ville Santé II Study. Int J Obes Relat Metab Disord. 2004;28(10):1227-32.

60. An JJ, Liao GY, Kinney CE, Sahibzada N, Xu B. Discrete BDNF Neurons in the Paraventricular Hypothalamus Control Feeding and Energy Expenditure. Cell Metab. 2015;22(1):175-88.

61. Ekelund U, Ward HA, Norat T, Luan J, May AM, Weiderpass E, et al. Physical activity and all-cause mortality across levels of overall and abdominal adiposity in European men and women: the European Prospective Investigation into Cancer and Nutrition Study (EPIC). Am J Clin Nutr. 2015;101(3):613-21.

\section{Acknowledgments}

The authors wish to thank the financial support provided by Fundação de Amparo à Pesquisa do Estado de São Paulo (FAPESP), São Paulo, SP, Brazil (process 2011/05932-3 and 2013/01624-8) and Coordenadoria de Aperfeiçoamento de Pessoal de Nível Superior (CAPES), Brasília, DF, Brazil.

\section{Corresponding author}

Camila Aparecida Machado de Oliveira

Universidade Federal de São Paulo, Campus Baixada Santista, Laboratório de Diabetes Experimental e Sinalização Celular, sala 325. Rua Silva Jardim 136, Vila Mathias, Santos, SP, Brazil

Email: cam.oliveira@unifesp.br

Manuscript received on August 30, 2016

Manuscript accepted on October 27, 2016

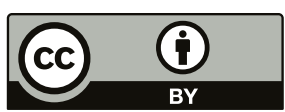

Motriz. The Journal of Physical Education. UNESP. Rio Claro, SP, Brazil - eISSN: 1980-6574 - under a license Creative Commons - Version 3.0 